\title{
Newer drugs keep multiple sclerosis patients out of wheelchairs - expert
}

There are fewer multiple sclerosis (MS) patients in wheelchairs than ever before in South Africa (SA), mainly owing to the advent of interferon drugs over the past decade and better second-line drugs over the past 3 years, says Prof. Girish Modi, Head of Neurology at the University of the Witwatersrand. He was responding to claims last month by the Biokinetics Association of South Africa (BASA) that physical activity helps manage symptoms and prevent complications and can perhaps even slow progression of MS.

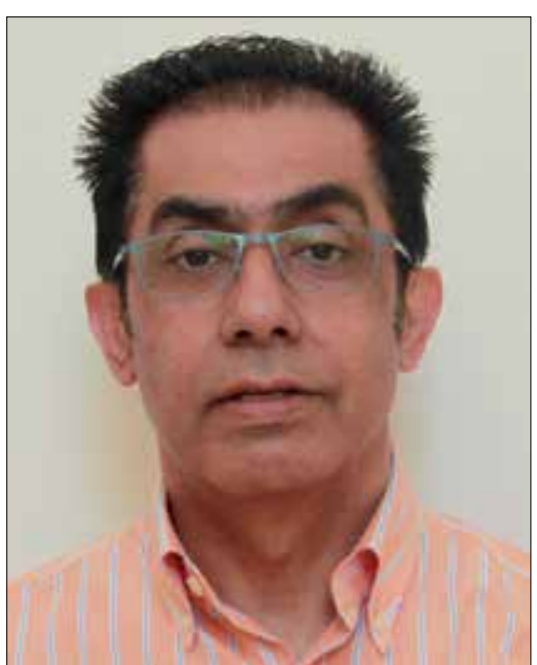

Prof. Girish Modi, Head of Neurology at the University of the Witwatersrand.

Last month (May) marked International Multiple Sclerosis Awareness Month, and Izindaba was testing assertions by
BASA that movement and exercise were therapeutic (contrary to decades-old 'wisdom' that exercise worsens MS). Modi, who is also Head of Neurology at Charlotte Maxeke Hospital in Johannesburg, said a sense of wellbeing had been shown to have 'some relevance' in autoimmune diseases, 'so a healthy lifestyle is a good thing, but there's no scientific evidence that exercise will reduce attacks or control the disease'. Areta Potgieter, an executive member of BASA and a practising biokineticist, had claimed that one of the most 'profound' recent changes in MS treatment and management related to exercise, with fatigue affecting $75-90 \%$ of all MS patients, many of whom avoided physical activity to try to reduce the symptoms of fatigue.

Medical aids had 'come to the party with interferon', and most MS sufferers in the private sector were now on it. Any patient who had had two or more MS attacks within the past 12 months should be on interferon, which cost ZAR7 000 - ZAR9 000 per month.

However, Modi said the most profound change was in pharmaceuticals, with interferon or the similar Copaxone becoming far more widely available in the private
Multiple sclerosis is a chronic, typically progressive disease that causes demyelination (disruption of the myelin that insulates and protects nerve cells) of spinal nerve and brain cells. The significant risk in the second-line drugs that Modi refers to is a condition known as progressive multifocal leucoencephalopathy (PML), caused by activation of what's called the JC virus in the brain - which can be fatal.

sector over the past decade. Second-line drugs such as Tysabri and Gilenya now helped modify the immune response and avoid relapse, though they carried some very significant risk. Evidence following the use of interferon 'clearly shows fewer people now in wheelchairs', he said. Medical aids had 'come to the party with interferon', and most MS sufferers in the private sector were now on it. Any patient who had had two or more MS attacks within the past 12 months should be on interferon, which cost ZAR7 000 - ZAR9 000 per month. Only 'a handful' of patients were on it in the public sector because of cost considerations. There are an estimated 5000 known MS sufferers in SA.

\section{Chris Bateman}

chrisb@hmpg.co.za

S Afr Med J 2016;106(6):543

DOI:10.7196/SAMJ.2016.v106i6.11039 